\title{
Flupenthixol and cefotiam: effects on vitamin A metabolism in rats
}

\author{
Rainer Schindler ${ }^{1}$, Tanja Fielenbach ${ }^{1}$ and Gerhard Rave ${ }^{2}$ \\ ${ }^{1}$ Department of Human Nutrition and Food Science and \\ ${ }^{2}$ Institute for Variationsstatistik, Christian-Albrechts-University zu Kiel, D-24105, Germany
}

(Received 27 February 2004 - Revised 1 June 2004 - Accepted 6 June 2004)

\begin{abstract}
We examined the alterations in vitamin A metabolism as a result of flupenthixol or cefotiam administration. The impact of these drugs on indices of vitamin A status was evaluated in Brown Norway and Long-Evans rats. Intramuscular drug administration for $28 \mathrm{~d}$ resulted in a decline in systemic retinol. Changes in circulating retinol with time for chronic dosing showed drug treatment $(P<0 \cdot 001)$ and time $(P<0.03)$ to be significant factors, but rat strain $(P=0.33)$ was not a significant factor. Flupenthixol was the most active retinol-lowering compound $(P<0.005)$. At the end of the $28 \mathrm{~d}$ period, hepatic retinyl ester hydrolase activity was greater in drug-treated rats than in controls $(P<0.05)$. With regard to effects on liver reserves: (1) flupenthixol treatment resulted in vitamin A depletion $(P<0 \cdot 05)$; $(2)$ cefotiam treatment stimulated vitamin A accumulation; (3) distinctive patterns of retinol and its esters were seen in response to treatment. It is reasonable to assume that the drugs interfere with vitamin A in at least two ways: (1) lowering of plasma retinol, an early event in the interaction, may be caused by inhibition of hepatic holo-retinol-binding protein secretion or stimulation of clearance, or both; (2) when plasma retinol levels are persistently low, and as the hepatic deposits of the xenobiotics build up, there are changes in the vitamin A pool size and composition of the liver. Candidate enzymes are retinyl ester hydrolase and cytochrome P450. The relationship between these two events will be studied in further detail.
\end{abstract}

Flupenthixol-vitamin A interaction: Cefotiam-vitamin A interaction: Retinyl ester hydrolase

Interactions between pharmacological agents and micronutrients, especially vitamin A, have gained wide interest. This is because vitamin A promotes general growth, epithelial cell differentiation, visual function, reproduction and immunocompetence in human subjects (Sporn et al. 1984). In human subjects, physico-chemical interactions between drug ingredients and vitamin A may arise as a consequence of a number of mechanisms, and are known to occur in situ at the site of entry and in transit or at storage sites. Examples include the reduction in bioavailability of lipid-soluble vitamins due to drug-bile acid complex formation (cholestyramin, neomycin, kanamycin and p-aminosalicylic acid) or pancreatic lipase inhibition (tetrahydrolipstatin) (Samuel et al. 1965; Faloon et al. 1966; Barnard \& Heaton, 1973; Fernández \& Borgström, 1990; Favaro et al. 1994). The lowering of serum retinol levels is another example of drugs altering vitamin A metabolism (Haubold et al. 1953; Smith et al. 1992). This secondary depletion of circulating retinol levels may contribute to night blindness, which has been reported after procaine penicillin or $N$-(4-hydroxyphenyl)retinamide (Fenretinide) administration (Haubold et al. 1953; Smith et al. 1992). Interference with the detoxifying system represents an alternative mode of action by which drugs interact with retinol metabolism at the microsomal level. Several therapeutic agents, including phenobarbital, methyldopa, prednisone, hydrocortisone, methadone, phenothiazine, phenytoin and cyclosporin $\mathrm{A}$, have been shown to be among the group of drugs known to induce hepatic vitamin A depletion in human subjects as well as in experimental animals (Leo et al. 1984, 1987; Azaïs et al. 1987). Part of the efficacy of some of the drugs mentioned earlier (i.e. phenobarbital and phenothiazine) in this context is probably due to induction of some forms of cytochrome P450 (CYP), a supergene family of haemoprotein enzymes that catalyse oxidation of xenobiotics, including vitamin $\mathrm{A}$ (Leo et al. 1984, 1987). With regard to the biotransformation of vitamin A, most studies have focused on CYP, but these vitamin A-metabolising enzymes are not the only ones in the decomposition pathway of retinyl esters. In addition, the liver contains several retinyl ester-splitting enzymes capable of hydrolysing chylomicron-derived (exogenous) retinyl ester or generating free retinol (vitamin A alcohol) from its storage form as esters (for review, see Harrison, 1998). The liberated retinol acts as precursor for re-esterification for storage (Blaner et al. 1985; Blomhoff et al. 1985), as a ligand for secretion with retinol-binding protein into plasma (Smith et al. 1998), as an intermediate for biosynthesis of retinoic acid (the final morphogenic derivative of vitamin A; Napoli \& Race, 1990) and as

\footnotetext{
Abbreviations: BN, Brown Norway; CYP, cytochrome P450; LE, Long-Evans; REH, retinyl ester hydrolase; RL, retinyl linoleate; RM, retinyl myristate; RO, retinyl oleate; RP, retinyl palmitate; RS, retinyl stearate.

* Corresponding author: Dr Rainer Schindler, fax +49 431880 5679, email rschindler@nutrfoodsc.uni-kiel.de
} 
substrate for oxidative reactions in the pathway for elimination of vitamin A from the body (Roberts et al. 1980). Thus, CYP isoforms and free retinol-generating enzymes function in sequence to catalyse the conversion of retinyl esters to more polar compounds.

As mentioned earlier, phenothiazine and procaine penicillin, members of two distinctly different therapeutic classes, have been recognised as vitamin A antagonists (Haubold et al. 1953; Leo et al. 1984). We wondered whether structural analogue compounds from both classes might also interfere with normal vitamin A metabolism in vivo. Against this background, flupenthixol (a psychotropic-neuroleptic agent) and cefotiam (a cephalosporin antibiotic) were selected to assess whether these compounds also adversely affect vitamin A status at doses comparable with those in clinical use. The thioxanthene drug, flupenthixol, has structural characteristics related to those of the phenothiazines and cefotiam shares structural features with penicillins. Flupenthixol, like other thioxanthene compounds, is used in the therapy of schizophrenia, organic psychoses and other idiopathic psychotic illnesses and is often administered for long periods; therapeutic efficacy is maximal 3-4 weeks following initial administration (Dollery, 1991). Due to the high tissue binding of flupenthixol, the serum level is low relative to the tissue concentration. The greatest flupenthixol levels have been found in liver, lungs, intestine and kidneys. Like other phenothiazine derivatives, flupenthixol is extensively metabolised in the liver before being excreted (Dollery, 1991). Besides flupenthixol, in our present study we also utilised cefotiam for comparative purposes. The pharmacological effect of cephalosporins is analogous to that of penicillins. This explains the wide use of cephalosporins in clinical practice. Once given by injection, they are rapidly circulated and penetrate tissues. Following intramuscular administration, $50-70 \%$ of the drug is excreted unchanged in the urine (Brogard et al. 1989). As a therapeutically relevant compound, cefotiam is the drug of choice for treatment of infections caused by susceptible Gram-positive and Gram-negative bacteria (e.g. treatment of peritonitis associated with continuous ambulatory peritoneal dialysis, biliary tract infections and perinatal infections). In cases of severe infection, the use of a cephalosporin antibiotic for up to $20 \mathrm{~d}$ is recommended (Perry \& Brogden, 1996). One of its advantages is that adverse reactions are rare; side effects include occasional reports of renal function abnormalities (Riegel \& Hörl, 1993).

Rats are the most common laboratory model for investigating vitamin A metabolism. However, inter-strain differences in both vitamin A metabolism and responsiveness to drug administration are known to exist among rats, making extrapolation of data from one strain to another difficult (Pirovino et al. 1990; Seifert et al. 1991; Lahmame \& Armario, 1996; Tuitoek et al. 1996; Schindler et al. 2002). Therefore, another factor considered when designing the present study was the rat strain. Since there are distinct differences in the expression of non-specific carboxylesterase isoforms among rat strains, experiments were conducted on two strains of laboratory rat: Brown Norway (BN) and Long-Evans (LE) (Bender et al. 1984; Hedrich, 1990).
Non-specific carboxylesterases are catalysts involved in hepatic processing of xenobiotics (Mentlein \& Heymann, 1984), and as detoxifying enzymes they operate in concert with CYP isozymes (see earlier). Two members of the non-specific carboxylesterase family have been shown to hydrolyse retinyl esters (i.e. bile-acid-independent carboxylesterase-4 and bile-acid-dependent retinol ester hydrolase (REH)) (Mentlein \& Heymann, 1987; Schindler et al. 1998). Of the two retinyl ester-splitting carboxylesterases, it is REH that will receive attention in the present paper, since flupenthixol and cefotiam are known to be in vitro REH inhibitors (Schindler, 2001). The objective of these experiments with $\mathrm{BN}$ and $\mathrm{LE}$ rats was to investigate the individual effects of flupenthixol and cefotiam on the metabolism of vitamin A in vivo. We report: (1) the sequential changes in the plasma retinol concentration during the $28 \mathrm{~d}$ exposure period; (2) the treatment-related effects on REH activity; (3) the hepatic vitamin A pool size and composition; (4) the amount of vitamin A within the kidneys.

\section{Experimental procedures}

\section{Sources of pharmacological agents, chemicals and experimental animals}

Therapeutic agents were obtained from manufacturers as follows: flupenthixol dihydrochloride from Troponwerke (Köln, Germany) and cefotiam dihydrochloride from Takeda Pharma (Stolberg, Germany). With the exception of retinyl palmitate (RP), which was a generous gift from Hoffman-La Roche (Basel, Switzerland), all specific reagents (i.e. stearoyl chloride, linoleoyl chloride, myristoyl chloride, oleoyl chloride) were purchased from Sigma (Deisenhofen, Germany). The suppliers of other reagents and chemicals have been reported earlier (Schindler et al. 2002). All chemicals and solvents were of analytical grade.

Male rats of the strains BN (body weight 243.4-346.8 g) and LE (body weight 337.9-452.9 g) were purchased from Zentralinstitut für Versuchstierzucht (Hannover, Germany). Rats were housed singly, in cages $(150 \times 270 \times 430 \mathrm{~mm})$ with mesh bases, in a temperature- and humidity-controlled environment with a $12 \mathrm{~h}$ light-dark cycle. During experiments, they were given free access to water and a standard rat chow (rodent diet no. 1314; Altromin, Lage, Germany) that contained adequate amounts of vitamin A $(15.77 \mu \mathrm{mol}$ retinol $/ \mathrm{kg} \mathrm{diet).} \mathrm{On} \mathrm{days} 0-28$, individual body weights were monitored daily. Care and treatment of the rats was approved by the Christian-Albrechts-University of Kiel Institutional Animal Care and Use Committee.

\section{Experimental design}

Three separate groups (six rats per group) of $\mathrm{BN}$ and $\mathrm{LE}$ rats were studied in a randomised experiment. One group, the placebo group, received an equivalent volume (i.e. $1.5 \mathrm{ml} / \mathrm{kg}$ body weight) of the dosing vehicle (i.e. saline, $150 \mathrm{mmol} \mathrm{NaCl} / \mathrm{l}$ ) only, the second group received flupenthixol and the third group received cefotiam. The pharmacological agents chosen for the present study were sufficiently soluble in physiological saline 
$(150 \mathrm{mmol} / \mathrm{l} \mathrm{NaCl})$ to be used in our present experiments. Solutions of the drugs were made fresh, protected from exposure to light, and stored at $4{ }^{\circ} \mathrm{C}$. The formulations were injected into the musculus quadriceps femoris daily for $28 \mathrm{~d}$ (Fig. 1) and the animals were observed until termination. The route of administration was based on clinical practice. Only one dosage of each drug (Table 1) was given to each animal. The doses of the test compounds that were chosen in the present study span the range used for therapeutic purposes. To illustrate this, we compiled corresponding data for the study drugs from a review of the available literature (Table 1; Dollery, 1991; Mutschler \& Schäfer-Korting, 1996). The doses administered to test animals were calculated from the recommended therapeutic doses for a human subject corrected to relative body surface area, according to Löscher et al. (1991). At the end of the $28 \mathrm{~d}$ study period the rats were killed with diethyl ether, and blood, liver and kidneys were collected. The organs were rinsed with ice-cold saline $(150 \mathrm{mmol}$ $\mathrm{NaCl} / \mathrm{l}$ ) containing $2.5 \mathrm{mmol}$ ascorbate $/ \mathrm{l}$ and $1.7 \mathrm{mmol}$ EDTA/l, blotted and weighed. The frozen plasma and tissue samples were stored in light-proof tubes at less than $-20^{\circ} \mathrm{C}$ for subsequent analyses.

\section{Determination of retinyl ester hydrolase activity and protein concentration}

Portions of liver $(2 \mathrm{~g})$ were homogenised with a PotterElvehjem homogeniser (Braun, Melsungen, Germany) in 5 vol. $0 \cdot 1 \mathrm{~mm}$-Tris-maleate buffer, $\mathrm{pH} \mathrm{7 \cdot 0.} \mathrm{The} \mathrm{homogenate}$

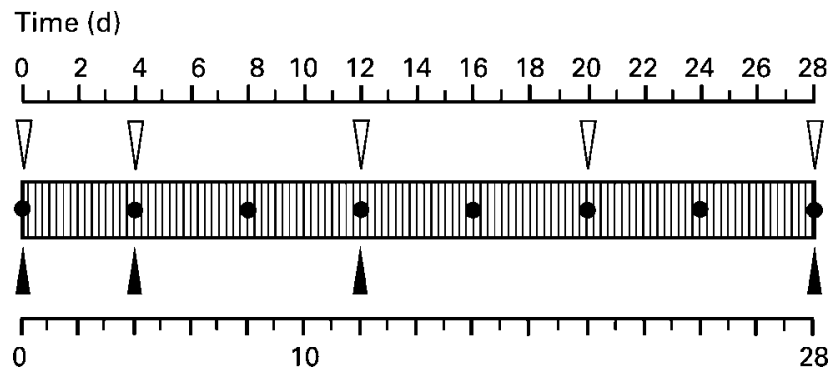

Fig. 1. Experimental design used in the present study. The bar shows the progression of the dosing experiment as a function of time. 四, Drug treatment; $\nabla$, blood collection for the assessment of plasma clinical chemistry; $\boldsymbol{\bullet}$, systemic retinol; $\boldsymbol{\Lambda}$, haematology. Pre-chronic dosing period days $0-8$, chronic dosing period days was then centrifuged at $50000 \mathrm{~g}$ for $5 \mathrm{~min}$ at $4^{\circ} \mathrm{C}$. Portions of the supernatant fraction were analysed for REH activity by a retinol-releasing assay detailed by Schindler et al. (1998). The reaction mixture consisted of $0.5 \mathrm{ml}$ Triton X-100 (2 mg/ml), 3-((3-cholamidopropyl)dimethylammonio)-1-propane-sulfonate $(200 \mathrm{mmol} / \mathrm{l})$, RP $(50 \mu \mathrm{mol} / \mathrm{l})$, Tris-maleate $(0 \cdot 1 \mathrm{~mol} / \mathrm{l}), \mathrm{pH} 7 \cdot 2$. The $60 \mathrm{~min}$ reaction at $37^{\circ} \mathrm{C}$ was started with the addition of the enzyme sample ( $2.4 \mathrm{mg}$ protein). After stopping the reaction with the addition of $0.5 \mathrm{ml}$ cold ethanol, the product was extracted from the reaction mixtures with $2 \mathrm{ml} n$-hexane containing butylated hydroxytoluene $(1 \mathrm{~g} / \mathrm{l})$. The upper phase was then evaporated under $\mathrm{N}_{2}$, dissolved in chloroform-methanol $(1 \cdot 5: 4 \cdot 0, \mathrm{v} / \mathrm{v})$ and analysed for retinol by reverse-phase HPLC as described later for plasma vitamin A determination. In this assay, the reaction rate was linear with regard to time and enzyme concentrations. In each assay, blank tubes (without enzyme) were used to correct for spontaneous hydrolysis of substrate. To prevent photodecomposition of vitamin $\mathrm{A}$, incubations were performed in light-protected, Teflon-lined, screw-capped tubes, under $\mathrm{N}_{2}$. An average of duplicate or triplicate analyses of each sample was used for this enzymic assay. Enzyme results are presented as specific activity. The protein content in the supernatant fraction was measured according to Bradford (1976) using bovine serum albumin as the standard.

\section{Extraction of tissue vitamin A (retinol plus retinyl esters)}

The estimation of vitamin A in portions of liver $(2 \mathrm{~g})$ or whole kidneys was carried out by homogenising each tissue in an equal volume of ice-cold saline $(150 \mathrm{mmol}$ $\mathrm{NaCl} / \mathrm{l})$ containing ascorbate $(2.5 \mathrm{mmol} / \mathrm{l})$ and EDTA $(1.7 \mathrm{mmol} / \mathrm{l})$ with an Ultra-Turrax homogeniser (Braun; detailed by Schindler et al. 1987). The emulsion was dried under vacuum and the residue was extracted four times with $5 \mathrm{ml}$ chloroform-methanol $(1 \cdot 0: 1 \cdot 0, \mathrm{v} / \mathrm{v})$ containing butylated hydroxytoluene $(230 \mu \mathrm{mol} / \mathrm{l})$. Before being loaded on an analytical HPLC column a sample of the combined chloroform-methanol layer was diluted 3fold with chloroform-methanol $(1 \cdot 0: 3 \cdot 2, \mathrm{v} / \mathrm{v})$. In the case of the kidneys, vitamin A was extracted with 5 vol. $n$ hexane containing butylated hydroxytoluene $(230 \mu \mathrm{mol} / \mathrm{l})$. Following solvent removal, samples were resuspended in $500 \mu \mathrm{l}$ chloroform-methanol $(1 \cdot 7: 4 \cdot 0, \mathrm{v} / \mathrm{v})$ and subjected to HPLC using the same procedure as described for

Table 1. Extravascular drug administration protocols

\begin{tabular}{|c|c|c|c|c|c|c|c|}
\hline $\begin{array}{l}\text { Application } \\
\text { route }\end{array}$ & Study group & $\begin{array}{l}\text { Treatment } \\
\text { duration }(d)\end{array}$ & $\begin{array}{l}\text { Drug dosage } \\
\text { regimen }\end{array}$ & $\begin{array}{r}\text { Dose } \\
(\mathrm{mg} / \mathrm{kg}\end{array}$ & $\begin{array}{l}\text { inistered } \\
\text { weight })^{\star} \dagger\end{array}$ & $\begin{array}{c}\text { Clinical daily } \\
\text { dose (regimen) } \ddagger\end{array}$ & Reference \\
\hline i.m. & $\begin{array}{l}\text { Vehicle control§ } \\
\text { Flupenthixol } \\
\text { Cefotiam }\end{array}$ & $\begin{array}{l}28 \\
28 \\
28\end{array}$ & $\begin{array}{l}0.5 \mathrm{ml} \text { once per } \mathrm{d} \\
0.5 \mathrm{ml} \text { once per } \mathrm{d} \\
0.5 \mathrm{ml} \text { once per } \mathrm{d}\end{array}$ & $\begin{array}{r}- \\
4 \cdot 0 \\
350 \cdot 0\end{array}$ & $\begin{array}{l}(42 \mathrm{mg}) \| \\
(3.7 \mathrm{~g}) \|\end{array}$ & $\begin{array}{c}3 \times 10 \mathrm{mg} \text { (p.o.) } \\
3-6 \mathrm{~g} \text { (i.m.) }\end{array}$ & $\begin{array}{l}\text { Dollery (1991) } \\
\text { Mutschler \& } \\
\text { Schäfer-Korting } \\
\text { (1996) }\end{array}$ \\
\hline
\end{tabular}

i.m., intramuscular; p.o., per os.

* The animals were weighed once per $d$, and the dose was adjusted if necessary.

† Vehicle fluid for dose solution preparation was physiological saline $(150 \mathrm{mmol} \mathrm{NaCl} / \mathrm{l})$.

$\ddagger$ Comparison of the therapeutically active doses as adapted from the literature (Dollery, 1991; Mutschler \& Schäfer-Korting, 1996).

$\S$ Control rats received the dosing vehicle (i.e. isotonic saline $(150 \mathrm{mmol} \mathrm{NaCl} / \mathrm{l}))$ only.

$\|$ Daily therapeutic dose corresponding to the average $65 \mathrm{~kg}$ adult human subject.

10-28. For details of procedures, see p. 598. 
plasma samples. The amount of unesterified retinol + retinyl esters (= total vitamin A) in the samples was expressed as retinol equivalents per $\mathrm{g}$ wet tissue.

\section{Estimation of plasma and tissue vitamin A levels}

Blood samples $(500 \mu \mathrm{l})$ were taken by tail clip using sodium heparin as an anticoagulant, and plasma was separated by centrifugation at $1500 \mathrm{~g}$ for $20 \mathrm{~min}$ at $4^{\circ} \mathrm{C}$. Systemic retinol was measured in the hexane-soluble plasma fraction after first precipitating protein with ethanol $(500 \mathrm{~g} / \mathrm{l}$; Schindler et al. 1985). A sample of the hexane layer was evaporated under $\mathrm{N}_{2}$ and the residue was resuspended in chloroformmethanol $(1 \cdot 5: 4 \cdot 0, \mathrm{v} / \mathrm{v})$. The retinol extracts were then analysed by reverse-phase HPLC using a fluorescence detector, with excitation and emission wavelengths of 325 and $480 \mathrm{~nm}$, respectively, and a Bio-Tek Kontron spherisorb ODS analytical HPLC column ( $5 \mathrm{~mm}$ internal diameter $\times 250 \mathrm{~mm}$; Bio-Tek Kontron, Neufahren, Germany). Isocratic elution was performed at a flow rate of $1.8 \mathrm{ml} / \mathrm{min}$ using methanol. Retinol and retinyl esters of the lipid extracts were identified according to the retention time against vitamin A standards, prepared from retinyl palmitate (RP) (i.e. retinol) or synthesised from corresponding fatty acyl chlorides in our laboratory (e.g. retinyl myristate (RM), linoleate (RL), oleate (RO) and stearate (RS)) according to known procedures (Ito et al. 1974; Huang \& Goodman, 1985). However, our method for measuring vitamin A quantitates RL + RM and $\mathrm{RP}+\mathrm{RO}$ as single peaks. Therefore, they were calculated and represented as two fractions. Stock solution of retinol (dissolved in light petroleum ether $\left(40-60^{\circ} \mathrm{C}\right)$ ), RM, RL, $\mathrm{RP}, \mathrm{RO}$ and RS (each dissolved in ethanol) standards were prepared as described previously (Schindler et al. 2002) and verified by the absorbance of a $1 \%$ solution at $325 \mathrm{~nm}$ 1830, 990, 900, 940, 890, 870 respectively (Thompson et al. 1971; Bhat \& Lacroix, 1983). All the HPLC analyses were performed at room temperature $\left(20 \pm 2^{\circ} \mathrm{C}\right)$.

\section{Haematology and clinical chemistry}

Haematological analyses included determinations of blood count, $\mathrm{Hb}$, packed cell volume, electrolytes (i.e. $\mathrm{Na}, \mathrm{K}, \mathrm{Cl}$ ), urea, creatinine and total plasma proteins. The variables, except for blood count, $\mathrm{Hb}$ and packed cell volume, were measured by automated laboratory procedures using a Hitachi 911-E automatic analyser (Hitachi Clinical Diagnostic Systems, Berlin, Germany).

\section{Statistical analyses}

The experiment was analysed as a completely randomised design with repeated measurement data for the traits systemic retinol and weight of rat, as indicated in Fig. 1. For modelling the covariance structure of the repeated measurement data, we used the SAS procedure MIXED (version 6.12, 1996; SAS Institute Inc., Cary, NC, USA) as described in our previous publication (Schindler et al. 2002). A suitable structure type was 'heterogeneous compound symmetry', i.e. equal correlation variances at each time of measurement. The analysed fixed effects were treatment (study group of Table 1), strain of rat, time of measurement (if repeated measurements were present) and corresponding effects of interaction. Because weight of rats differed between treatment groups, a correction was made by analysis of covariance technique with initial weight as covariate. Results are reported as estimated mean values with their standard errors in the text; unless otherwise indicated, $P<0.05$ was regarded as significant.

\section{Results}

All animals completed the administration protocol. No adverse effects of either drug on the general health or appearance of the rats, or on the morphology of the major organs, were observed throughout the study.

The growth curves of the experimental animals are shown in Fig. 2. However, inspection of Fig. 2 indicates that the BN and LE rats used in this series were strikingly different from each other in terms of initial body weight. Therefore, initial body weight was used as a covariate in the statistical ANOVA. Estimated mean values indicated that there were no significant differences in the time course of changes in body weight during the pre-chronic dosing phase, except for flupenthixol-treated LE rats, which weighed $13 \%$ less than baseline at the end of the acute treatment period (day 8). In contrast to flupenthixol-treated LE rats, whose body weights increased significantly by $\geq 13 \%$ during chronic drug treatment, the body weights of the other experimental animals remained relatively stable throughout the late study period.

In order to document in more detail the influence of the experimental drugs on systemic retinol, the present study focused on acute (days 0-8; cf. Fig. 3) and more chronic (days 12-28; cf. Fig. 3) changes in plasma retinol concentration during the $28 \mathrm{~d}$ drug treatment. Analysis of systemic retinol levels revealed that both flupenthixol and cefotiam treatment produced perturbations in plasma retinol homeostasis. As shown in Fig. 3, plasma retinol concentrations decreased in response to treatment (acute drug effect, $P<0.001)$ independent of gavage-related stress starting on day 0 , and remained low relative to baseline throughout the early study period (days $0-8)$. In addition, main effects of rat type $(P<0.003)$ and time $(P<0.001)$ as well as significant drug $\times$ time $(P=0.002)$ and strain $\times$ time $(P<0.001)$ interactions were observed. The interaction term in the ANOVA for drug and strain was also significant $(P<0 \cdot 012)$, i.e. the retinol-lowering effect of the drugs was much more effective in LE rats. Examination of the drug $\times$ strain estimated mean values showed that retinol concentrations during the first $8 \mathrm{~d}$ were lower for flupenthixol- and cefotiam-treated LE rats than for corresponding vehicle-treated controls. Plasma retinol levels in LE rats, however, were also found to be lower in the flupenthixol group compared with the cefotiam group.

The response to chronic treatment (days 12-28) was similar in $\mathrm{BN}$ and LE rats (strain effect, $P=0 \cdot 33$ ). Systemic retinol levels in drug-treated rats were lower than in vehicle-treated controls and remained so until day 28. For plasma retinol measured on days 12, 16, 20, 24 and 28 , significant main effects of drug $(P<0.001)$ and time $(P<0.03)$, as well as significant interactions of drug $\times$ time $(P<0.02)$ and strain $\times$ time $(P<0.05)$, were observed. Estimated mean values indicated that the drug effect was 


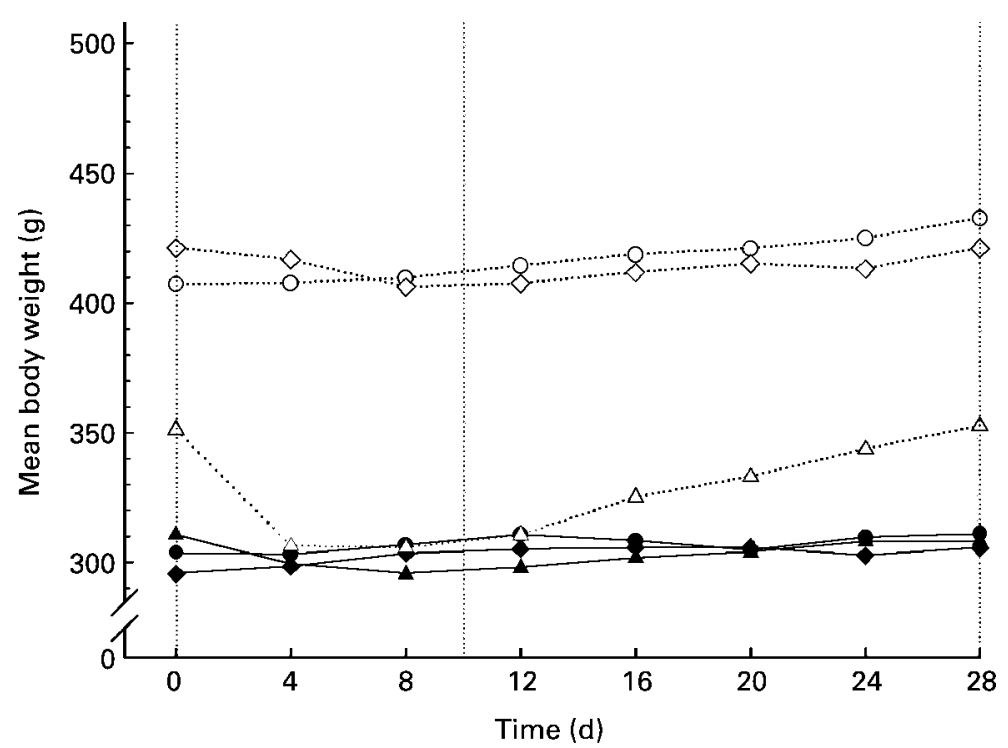

Fig. 2. Mean body weight changes for Brown Norway (BN) and Long-Evans (LE) rats during the $28 \mathrm{~d}$ study period. Eighteen rats of each strain (BN initial weight $243.4-346.8 \mathrm{~g}$; LE initial weight $337.9-452.9 \mathrm{~g}$ ) were allocated randomly to the following groups: dosing vehicle (i.e. physiological saline; $150 \mathrm{mmol} \mathrm{NaCl/l)}$; flupenthixol $(4 \mathrm{mg} / \mathrm{kg}$ body weight); cefotiam ( $350 \mathrm{mg} / \mathrm{kg}$ body weight). For clarity, mean values are shown for two time intervals (treatment as shown in Fig. 1). : Start of drug treatment (day 0), the beginning of chronic dosing (day 10) and the

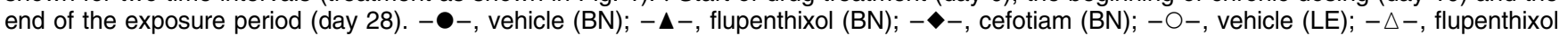

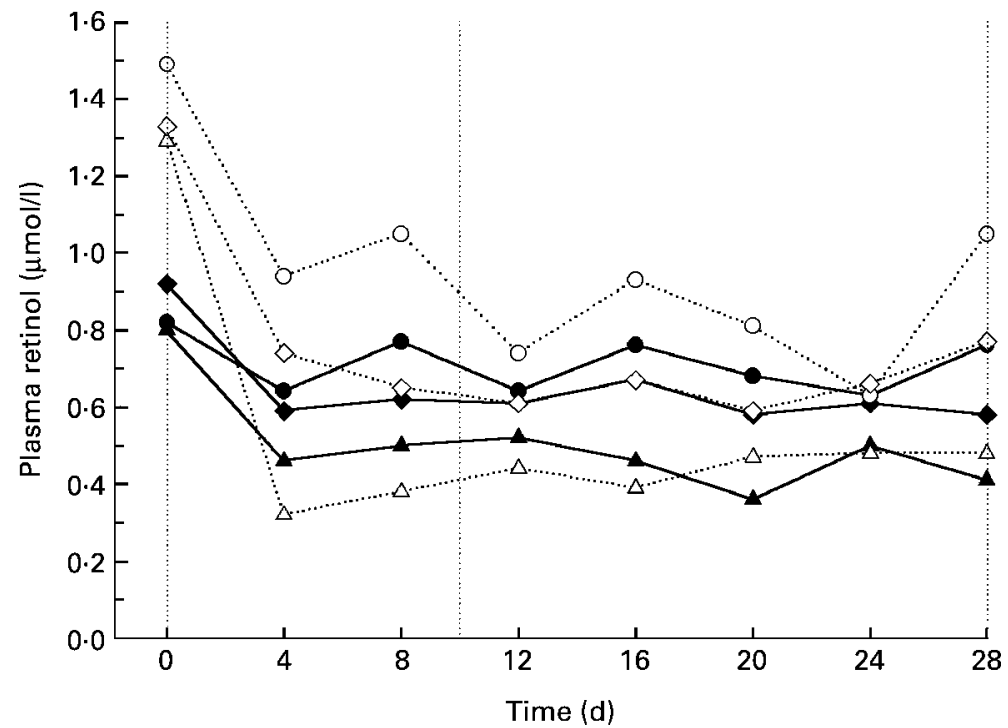

Fig. 3. Changes in the level of plasma retinol in Brown Norway (BN) and Long-Evans (LE) rats with time. Separate groups $(n 6)$ of BN and LE rats were administered intramuscular physiological saline (dosing vehicle, $150 \mathrm{mmol} \mathrm{NaCl} / \mathrm{l}$ ), flupenthixol (4 mg/kg body weight) or cefotiam $(350 \mathrm{mg} / \mathrm{kg}$ body weight) once per d for $28 \mathrm{~d}$. For clarity, estimated mean values are shown for two time intervals (blood collection and treatment as shown in Fig 1). $\vdots$, Start of drug treatment (day 0), the beginning of chronic dosing (day 10) and the end of the exposure period (day 28). - - -, vehicle (BN); - $\Delta-$, flupenthixol (BN); - - , cefotiam (BN); $-O-$, vehicle (LE); $-\triangle-$, flupenthixol (LE); $-\diamond-$, cefotiam (LE). Prechronic dosing period days $0-8$, chronic dosing period days 10-28. For details of procedures, see p. 598. For systemic retinol measured on days 0 , 4 and 8 , significant main effects of drug $(P<0.001)$, time $(P<0.001)$ and rat type $(P<0.003)$ were observed. The change in circulating retinol concentrations from days 12-28 also showed significant main effects of drug $(P<0.001)$ and time $(P<0.03)$, but not of rat strain $(P=0.333)$. For a detailed explanation of significant pair-wise comparisons and interactions, see p. 600 .

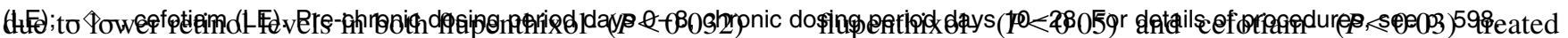
and cefotiam- $(P<0.001)$ treated rats compared with vehicle-treated controls. Furthermore, the observed retinol-lowering effect of flupenthixol was more pronounced than that seen for cefotiam $(P<0.005)$.

At the end of the study, we tested the possible effects of the two drugs on REH activity, and found that both rats had more REH activity than corresponding controls (Table 2). These results establish for the first time that REH activity is up-regulated by flupenthixol and cefotiam.

Because the liver is the major source of plasma retinol, it was also considered important to determine the levels of non-esterified and esterified retinol in the liver to 
understand more about the control mechanisms that regulate release of hepatic retinol. The size and composition (vitamin A pattern) of liver vitamin A stores are therefore also given in Table 2. Treatment of $\mathrm{BN}$ and LE rats with flupenthixol once per $\mathrm{d}$ for $28 \mathrm{~d}$ resulted in a very pronounced decline in hepatic vitamin A concentration $(P=0.001)$. Closer inspection of Table 2 shows that the percentage of total vitamin A present as non-esterified retinol in the liver was greater in the drug-treated rats compared with non-drug-treated rats, and this difference was more conspicuous in flupenthixol-treated LE rats $(P<0.005)$. The hepatic vitamin A ester profile was characterised by a high content of RP-RO. As a result, the relative amount of these long-chain fatty acyl esters was unaffected by drug exposure, but not by chronic flupenthixol treatment, in LE rats. However, the decreasing effect of flupenthixol on the proportion of RP-RO $(P=0 \cdot 001)$ was compensated for by opposing changes in the relative amount of RL-RM $(P<0 \cdot 01)$. Finally, it was shown, that cefotiam treatment was associated with an additional reduction of the RS fraction $(P<0 \cdot 007)$.

Besides liver, non-esterified retinol and retinyl ester concentrations were also measured in the kidney, which is a target organ for vitamin A. However, animals of both rat strains did not have abnormal levels of vitamin A in this extrahepatic tissue following flupenthixol or cefotiam treatment (Table 2). Thus, although plasma retinol levels were decreased in drug-treated rats, retinol was transported efficiently to the peripheral tissues of these animals. Moreover, it should be noted that genetically determined differences exist in kidney vitamin A between $\mathrm{BN}$ and LE rats $(P=0 \cdot 008)$.

\section{Discussion}

In 1953, a clinically relevant pharmacokinetic interaction of the anti-bacterial agent procaine penicillin with vitamin A in healthy individuals was described by Haubold et al. (1953). Another finding of that study was the observation that the fall in retinol levels coincided with defects in dark adaptation. The mechanism of the procaine penicillin-vitamin A incompatibility is unknown. This is in contrast to what has been reported for phenothiazine and some other drugs (Leo et al. 1984). In these cases, liver reserves of vitamin A may be reduced by induction of hepatic metabolism. To date, no other penicillin and phenothiazine family members have been carefully and fully characterised for their ability to modulate vitamin A metabolism locally. For these reasons, the present study was undertaken to examine whether administering flupenthixol or cefotiam, drugs similar (both chemically and in their mode of action) to phenothiazine and penicillin, respectively, could modify the levels of vitamin A in plasma and liver. The results reported here suggesting that the pharmacological probes may indeed be vitamin A antagonists are somewhat inconsistent with the fact that these agents, which are used widely in clinical practice, are perceived as being relatively safe compounds (Brogard et al. 1989; Dollery, 1991).

A shortcoming of the present study might be the weight differences with regard to treatment groups; the body 
weight of flupenthixol-treated LE rats was significantly lower than those of the LE cefotiam-treated group or the LE control group (Fig. 2). Body weight was, however, not significantly correlated to the systemic vitamin A values and, consequently, the weight differences appear not to influence the changes in the retinol level with time (Fig. 3). The growth pattern shown only by the flupenthixol-treated LE rats is again somewhat puzzling. The observed changes in body weight, initially dropping and then returning to pre-treatment values, are not consistent with the hypothesis that administration-related stress is a critical factor in the promotion of growth retardation seen in these animals. In a study of the safety of flupenthixol in male Sprague-Dawley rats, a single intraperitoneal injection $(0.3 \mathrm{mg} / \mathrm{kg})$ caused decrements in the free-feeding behaviour and in the locomotor-exploratory activity of the animals (Pitts \& Horvitz, 2000). It is therefore likely that the flupenthixol-induced weight loss in young LE rats observed in our present study can be explained by the appetite-suppressive effect of this pharmaceutical agent. In comparison with $\mathrm{LE}$ rats, $\mathrm{BN}$ rats were resistant to flupenthixol-induced weight loss. We can only speculate on the reason for this apparent discrepancy. One possibility is that these results reflect a genetically determined difference in susceptibility to flupenthixol anorexia. Genetic factors, such as rat strain, also appear to contribute to the response of plasma retinol levels to stressful situations (e.g. injection-related discomfort, diethyl ether anaesthesia and wounding). In particular, the plasma retinol levels fall within hours and are depressed at day 4 in all blood samples compared with those at time zero (Fig. 3). The fall in plasma retinol in the controls, however, was not as pronounced as that seen in the treatment groups, and at days 8-28 the concentration was significantly increased compared with the value at day 4 . The transitory marked dip of plasma retinol in the pre-chronic dosing period, followed by a gradual rise in the chronic dosing period despite continued physiological stress, points to a metabolic adaptation. The difference in the magnitudes of change also indicates that strain differences exist in response to stress, with LE more affected than BN. One proposed mechanism underlying the immediate drop of plasma vitamin A after initiation of treatment is an impaired synthesis and/or secretion of carrier protein (i.e. retinol-binding protein, a negative acute-phase reactant protein; Schindler et al. 2003) from the liver. In view of the short exposure time, it is probable that the experimental drugs reach the liver at a low concentration, which is, however, sufficiently high to exert the retinollowering effect found. Another rate-limiting step in the output pathways is at the level of the enzyme-catalysed generation of non-esterified retinol. The liver is thought to express several retinyl ester-splitting enzymes, including $\mathrm{REH}$, that appear genetically, physiologically and biochemically distinct (Harrison, 1998). Because flupenthixol and cefotiam have been shown to inhibit purified liver REH (Schindler, 2001), one might also have expected both agents to inactivate the enzyme in vivo after treatment for $28 \mathrm{~d}$. Surprisingly, the drugs caused an increase in $\mathrm{REH}$ activity, suggesting an induction of enzyme protein in these animals. It may be hypothesised that the increased biosynthesis of this hydrolase represents a compensatory mechanism resulting from its inhibition. The small increases in REH activities, however, were not accompanied by increased recovery of systemic retinol to pre-treatment levels. Thus, REH either does not normally contribute substantially to the maintenance of steady-state circulating retinol levels or the changes in REH activity were not of great enough magnitude to cause a corresponding rise in plasma retinol concentrations. However, the lack of a significant rise in intrahepatic retinol concomitant with the increase in REH activity was interpreted to mean that at least in flupenthixol-treated rats retinol expenditure (via elimination route) was favoured. Within this context, one has to remember that flupenthixol is an antipsychotic drug of the thioxanthene class, with pharmacokinetics characterised by an extensive distribution to hepatic tissue and a significant elimination via liver (Dollery, 1991). However, safety testing of phenothiazine neuroleptics, such as phenothiazine, chlorpromazine and promazine indicates that these thioxanthene-like compounds are inducers of certain CYP. CYP enzymes reported to be induced by these drugs include: CYP1A1, CYP1A2 and members of the 2B and 3A series by phenothiazine (Thomas et al. 1983; Tateishi et al. 1999); CYP1A1, CYP1A2, CYP2B1 and members of the $3 \mathrm{~A}$ subfamily by chlorpromazine (Thomas et al. 1983; Murray, 1992; Tateishi et al. 1999); CYP1A1, CYP1A2 and CYP2B1 by promazine (Murray, 1992). Since these CYP isoforms are thought to play a role in vitamin A oxidation (Leo \& Lieber, 1985; Martini \& Murray, 1993; Ahmad et al. 2000), such induction may be a link to explain the vitamin A depletion seen in flupenthixol-treated rats. Under conditions in which an excess of retinol enters the degradation pathway, its local availability as ligand for retinol-binding protein may be lowered. If the increase in retinol degradation in rats treated with flupenthixol was accompanied by a temporary loss of intrahepatic retinol, it could also well account for the extremely low plasma retinol levels observed compared with both cefotiam-treated and non-treated rats. Also of interest concerning the fall in hepatic vitamin A concentrations is that flupenthixol-treated LE rats began to gain weight $13 \mathrm{~d}$ after initiation of treatment. Therefore, the reduction of vitamin $\mathrm{A}$ in the liver of the growing rats may also be the result of an increased metabolic demand for retinoic acid by the extrahepatic tissues.

In contrast to the pharmacokinetics of flupenthixol, the properties of cefotiam include stability against hepatic metabolism (Brogard et al. 1998). Accordingly, a review of the literature failed to reveal any case where cefotiam is considered to be an agent that modulates CYP function or expression. Consistent with this suggestion, the present investigation has revealed that the semi-synthetic parenteral cephalosporin, cefotiam, at the dose selected, failed to induce hepatic vitamin A depletion. To be exact, the decreasing effect of cefotiam on the circulating retinol levels was compensated for by opposing changes, leading to enhanced deposition of vitamin $A$ in the liver (Table 2). This observation again supports our suggestion about the mechanism underlying the immediate drop of plasma vitamin A after initiation of treatment (see earlier). Another possibility is that the fall in plasma retinol is due 
to the nephrotoxicity of cefotiam. However, dialysis patients are characterised by elevated circulating concentrations of retinol (Werb et al. 1979; Vannucchi et al. 1992). This is in contrast to what has been observed in our present study. Therefore, renal dysfunction is unlikely to account for the decrease in plasma retinol concentrations in the cefotiam group relative to the control group.

Changes in hepatic retinyl ester composition require a concerted adaptation of vitamin A metabolism, adjusted by hydrolytic and synthetic activities for esterified retinol. Therefore, this and a previous study (Schindler et al. 2002) also sought to determine whether in vivo dosing with REH inhibitors can produce subsequent alterations in liver vitamin A ester profile. The major finding of this and our earlier (Schindler et al. 2002) investigation was that treatment of LE rats with naftidrofuryl or erythromycin caused a considerable increase in the relative amount of RP and RO, mainly at the expense of other retinyl esters. Flupenthixol depressed the level of these esters, whereas cefotiam was without effect on the RP-RO fraction. Studies in BN rats with naftidrofuryl and erythromycin yielded comparable results in that they enhanced the RP-RO content, whereas flupenthixol and cefotiam failed to show such a uniform effect. Whether the effects of flupenthixol and cefotiam are strain-related remains to be seen. Finally, the present results confirm that $\mathrm{BN}$ rats also differ from LE rats in their liver and kidney storage of vitamin A. An explanation for retinoid accumulation in the livers of the lighter BN rats may be a decreased output of retinol from the liver as a result of lower metabolic needs. Included in the evidence supporting this proposal is the observation that the kidneys contained lower amounts of vitamin $\mathrm{A}$ in $\mathrm{BN}$ than in LE rats.

Even if the present findings cannot be extrapolated to the human situation, they provide useful information about responses to dosing with flupenthixol or cefotiam. For example, they prove that flupenthixol is a more potent vitamin A antagonist than cefotiam. In the clinical praxis, multiple concomitant medication is usually given when highly potent neuroleptics, such as flupenthixol, are administered. Flupenthixol, like some of the co-administered drugs, is also used chronically, and potential for xenobiotic-vitamin $A$ and drug-drug interactions exists. In some instances such interactions may lead to vitamin A deficiency secondary to induction of the microsomal retinol-metabolising system. However, thioxanthenes are such widely used neuropeptics that knowledge of the flupenthixol-vitamin A incompatibility could be of benefit to clinicians.

\section{References}

Ahmad M, Nicholls PJ, Smith HJ \& Ahamadi M (2000) Effect of P450 isozyme-selective inhibitors on in-vitro metabolism of retinoic acid by rat hepatic microsomes. J Pharm Pharmacol 52, 311-314.

Azaïs V, Rachman F, Gros S, Pascal G \& Amédée-Manesme O (1987) Cyclosporine administration decreases liver vitamin A stores in normal and vitamin A-deficient rats. Drug Nutr Interact 5, 81-88.

Barnard DL \& Heaton KW (1973) Bile acids and vitamin A absorption in man: the effect of two bile acid-binding agents, cholestyramine and lignin. Gut 14, 316-318.
Bender K, Adams M, Baverstock PR, et al. (1984) Biochemical markers in inbred strains of the rat (Rattus norvegicus). Iтmиnogenetics 19, 257-266.

Bhat PV \& Lacroix A (1983) Separation and estimation of retinyl fatty acyl esters in tissue of normal rat by high-performance liquid chromatography. J Chromatogr 272, 269-278.

Blaner WS, Hendriks HFJ, Brouwer A, Leeuw AM, Knook DL \& Goodman DS (1985) Retinoids, retinoid-binding proteins, and retinyl palmitate hydrolase distribution in different types of rat liver cells. J Lipid Res 26, 1241-1251.

Blomhoff R, Rasmussen M, Nilsson A, et al. (1985) Hepatic retinol metabolism. J Biol Chem 260, 13560-13565.

Bradford MM (1976) Rapid and sensitive method for quantitation of microgram quantities of protein utilizing the principle of protein-dye binding. Anal Biochem 72, 248-254.

Brogard JM, Jehl F, Willemin B, Lamalle AM, Blickle JF \& Moteil H (1989) Clinical pharmacokinetics of cefotiam. Clin Pharmacokinet 17, 163-174.

Dollery C (1991) Therapeutic Drugs, vol. 1, pp. F79-F83. Edinburgh: Churchill Livingstone.

Faloon WW, Paes IC, Woolfolk D, Nankin H, Wallace K \& Haro EN (1966) Effect of neomycin and kanamycin upon intestinal absorption. Ann NY Acad Sci 132, 879-887.

Favaro RMD, Silva HS \& Vannucchi H (1994) Bioavailability of vitamin $\mathrm{A}$ in the rat following ingestion of neomycin sulfate or aluminium hydroxyde. Int J Vitam Nutr Res 64, 98-103.

Fernández E \& Borström B (1990) Intestinal absorption of retinol and retinyl palmitate in the rat. Effect of tetrahydrolipstatin. Lipid 25, 549-552.

Harrison EH (1998) Lipases and carboxylesterases: possible roles in the hepatic metabolism of retinal. Annu Rev Nutr 18, 259-276.

Haubold H, Loew W \& Kolb E (1953) Einwirkung von Penicillin auf den Vitamin A - Gehalt des Serums sowie auf die Nachtsichtigkeit. Münchner Med Wochenschr 95, 792-796.

Hedrich HJ (1990) Genetic Monitoring of Inbred Strains of Rats, pp. 322-332. Stuttgart: Gustav Fischer Verlag.

Huang HS \& Goodman DS (1985) Vitamin A and carotenoids. J Biol Chem 240, 2839-2844.

Ito YL, Zile M, Ahrens H \& DeLuca HF (1974) Liquid-gel partition chromatography of vitamin A compounds; formation of retinoic acid from retinyl acetate in vivo. J Lipid Res 15, 517-524.

Lahmame A \& Armario A (1996) Differential responsiveness of inbred strains of rats to antidepressants in the forced swimming test: Are Wistar Kyoto rats an animal model of subsensitivity to antidepressants? Psychopharmacology 123, 191-198.

Leo MA \& Lieber CS (1985) New pathways for retinol metabolism in liver microsomes. J Biol Chem 260, 5228-5231.

Leo MA, Lowe N \& Lieber CS (1984) Decreased hepatic vitamin A after drug administration in men and in rats. Am J Clin Nutr 40, 1131-1136.

Leo MA, Lowe N \& Lieber CS (1987) Potentiation of ethanolinduced hepatic vitamin A depletion by phenobarbital and butylated hydroxytoluene. J Nutr 117, 70-76.

Löscher W, Ungemach FR \& Kroker R (1991) Grundlagen der Pharmakotherapie bei Haus- und Nutztieren, pp. 342-343. Berlin and Hamburg: Verlag Paul Parey.

Martini R \& Murray M (1993) Participation of P450 3A enzymes in rat hepatic microsomal retinoic acid 4-hydrolylation. Arch Biochem Biophys 303, 57-66.

Mentlein R \& Heymann E (1984) Hydrolysis of ester- and amidetype drugs by the purified isoenzymes of nonspecific carboxylesterase from rat liver. Biochem Pharmacol 33, 1243-1248.

Mentlein R \& Heymann E (1987) Hydrolysis of retinyl esters by non-specific carboxylesterases from rat liver endoplasmic reticulum. Biochem J 245, 863-867. 
Murray M (1992) Inhibition and induction of cytochrome P450 2B1 in rat liver by promazine and chlorpromazine. Biochem Pharmacol 44, 1219-1222.

Mutschler E \& Schäfer-Korting M (1996) Arzneimittelwirkungen, 7th ed., pp. 670, Stuttgart: Wissenschaftliche Verlagsgesellschaft $\mathrm{mbH}$.

Napoli JL \& Race KR (1990) Microsomes convert retinol and retinal into retinoic acid and interfere in the conversion catalyzed by cytosol. Biochim Biophys Acta 1034, 228-232.

Perry CM \& Brogden RN (1996) Cefuroxime axetil. Drugs 52, $125-158$.

Pirovino M, Honegger U, Müller O, Zysset Th, Küpfer A, Tinel A \& Pessayre D (1990) Differences in hepatic drug accumulation and enzyme induction after chronic amiodarone feeding of two rat strains: role of the hydroxylator phenotype? Br J Pharmacol 99, 35-40.

Pitts SM \& Horvitz JC (2000) Similar effects of $D_{1} / D_{2}$ receptor blockade on feeding and locomotor behaviour. Pharmacol Biochem Behav 65, 433-438.

Riegel W \& Hörl WH (1993) Potenielle nephrotoxizität von cephalosporinen der 2. Generation: cefuroxim versus cefotiam. Infection 21, Suppl., S14-S16.

Roberts AB, Lamb LC \& Sporn MB (1980) Metabolism of all-trans retinoic acid in hamster liver microsomes. Oxidation of 4-hydroxy to 4-keto retinoic acid. Arch Biochem Biophys 199, 374-383.

Samuel P, Hobart C \& Shalchi OB (1965) Serum cholesterol reduction by para-aminosalicylates in man. I-131 triolein absorption studies. Proc Soc Exp Biol Med 118, 654-658.

Schindler R (2001) Inhibition of purified pig and human liver retinyl ester hydrolase by pharmacologic agents. Lipids 36, 543-548.

Schindler R, Berndt S, Schroeder P, Oster O, Rave G \& Sievers $\mathrm{H}-\mathrm{H}$ (2003) Plasma vitamin E and A changes during cardiopulmonary bypass and in the postoperative course. Langenbecks Arch Surg 387, 372-378.

Schindler R, Fielenbach T, Rave G, Blömer A \& Kellersmann R (2002) Vitamin A metabolism is altered in Brown Norway and Long-Evans rats infused with naftidrofuryl or erythromycin intravenously. Int J Vitam Nutr Res 72, 210-220.

Schindler R, Klop A, Gorny C \& Feldheim W (1985) Comparison between three fluorometric micromethods for determination of vitamin A in serum. Int J Vitam Nutr Res 55, 25-34.

Schindler R, Mentlein R \& Feldheim W (1998) Purification and characterization of retinyl ester hydrolase as a member of the non-specific carboxylesterase supergene family. Eur J Biochem 251, 863-873.

Schindler R, Scholz M \& Feldheim W (1987) Determination of vitamin $\mathrm{A}$ in liver sausage and liver tissue from slaughtered animals using HPLC. $Z$ Lebensm Unters Forsch 185, $208-212$.

Seifert WF, Bosma A, Hendricks HFJ, Blaner WS, van Leuwenvan RE, van Thiel-de Ruiter GCF, Wilson JHP, Knook DL \& Brouwer A (1991) Chronic administration of ethanol with high vitamin A supplements in a liquid diet to rats does not cause liver fibrosis. J Hepatol 13, 249-255.

Smith JE, DeMoor LM, Green EL \& Ritter SJ (1998) The complex between retinol and retinol-binding protein is formed in the rough microsomes of liver following repletion of vitamin A-depleted rats. Biochem Biophys Acta 1380, 10-20.

Smith JE, Lawless DC, Green MH \& Moon RC (1992) Secretion of vitamin A and retinol-binding protein into plasma is depressed in rats by N-(4-hydroxyphenyl)retinamide (Fenretinide). J Nutr 122, 1999-2009.

Sporn MB, Roberts AB \& Goodman DWS (1984) The Retinoids, 1st ed., vols 1 and 2. London: Academic Press.

Tateishi T, Kumai K, Watanabe M, Tanaka M \& Kobayashi S (1999) A comparison of the effect of five phenothiazines on hepatic CYP isozymes in rats. Pharmacol Toxicol 85, $252-256$.

Thomas PE, Reik LM, Ryan DE \& Levin W (1983) Induction of two immunochemically related rat liver cytochrome P-450 isozymes, cytochromes P-450c and P-450d, by structurally diverse xenobiotics. J Biol Chem 258, 4590-4598.

Thompson JN, Erdody P, Brien R \& Murray TK (1971) Fluorometric determination of vitamin $\mathrm{A}$ in human blood and liver. Biochem Med 5, 67-89.

Tuitoek PJ, Lakey JRT, Rajotte RV \& Basu TK (1996) Strain variation in vitamin A (retinol) status of streptozotocin-induced diabetic rats. Int J Vitam Nutr Res 66, 101-105.

Vannucchi MIT, Vannucchi H \& Humphreys M (1992) Serum levels of vitamin A and retinol binding protein in chronic renal patients treated by continuous ambulatorial peritoneal dialysis. Int J Vitam Nutr Res 62, 107-112.

Werb R, Clark WF, Lindsay RM, Jones EOP \& Linton AL (1979) Serum vitamin A levels and associated abnormalities in patients on regular dialysis treatment. Clin Nephrol 12, $63-68$. 